\title{
Os modos de vida das musicistas no Rio de Janeiro oitocentista
}

The ways of life of 19 th-century female musicians in Rio de Janeiro

\author{
Alexandro Henrique Paixão* \\ Patricia Amorim de Paula**
}

\begin{abstract}
Resumo - O objetivo deste artigo é apresentar os modos de vida das mulheres que viviam no Rio de Janeiro oitocentista e dedicaram parte de sua vida à carreira musical. Elas foram professoras de piano e de canto, intérpretes e compositoras, mas seus nomes não estão inscritos na história da música brasileira. O esforço metodológico consiste em recuperá-los dentre as páginas da imprensa fluminense e, assim, mapear fragmentos dessa história para que ela sobreviva à ação do tempo. O ponto é colocar a versão oficial da história em perspectiva, trazendo novos elementos relativos à participação dessas mulheres na vida social, revelando aspectos de suas vidas que podem contribuir para a construção de uma nova narrativa sobre a cena musical no Rio de Janeiro oitocentista.
\end{abstract}

Palavras-chave: musicistas; estudos de gênero; imprensa oitocentista; Rio de Janeiro.

\begin{abstract}
The aim of this article is to present the ways of life of women who lived in Rio de Janeiro in the 19th century and dedicated part of their life to their musical careers. They were piano and singing teachers, performers, and composers, but their names have not been inscribed in the history of Brazilian music. The methodological effort consists of retrieving them from the pages of the Rio de Janeiro press, thus mapping fragments of history so that they survive the action of time. The point is putting the official version of history in perspective by bringing new elements concerning the participation of these women in social life, unveiling aspects of their lives that may contribute to the construction of a new narrative concerning the musical scene in Rio de Janeiro in the 19 th century.

Keywords: female musicians; gender studies; 19th-century press; Rio de Janeiro.
\end{abstract}

\footnotetext{
* Sociólogo, Doutorado em Sociologia, Pós-Doutorado em Teoria e História Literária e Especialização em Psicanálise: Teoria e Técnica. Professor de Sociologia, Literatura e Psicanálise da Faculdade de Educação da Unicamp. E-mail: ahpaixao@unicamp.br.ORCID: https://orcid.org/0000-0003-1684-3611.

** Pedagoga e Mestra em Educação pela Faculdade de Educação da Unicamp. É doutoranda na Faculdade de Educação da Unicamp com bolsa da Fundação de Amparo à Pesquisa do Estado de São Paulo (Fapesp). E-mail: paula apatricia1@hotmail.com. ORCID: <https://orcid.org/0000-0003-4039-6305.
} 


\section{Introdução}

Como instância de consagração, a historiografia musical, até hoje, apresenta poucos registros sobre a participação feminina no cenário musical carioca dos oitocentos. Muito embora saibamos que a constituição de grupos sociais artísticos brasileiros nesse tempo e espaço contou com a participação social de ambos os sexos, o problema eminentemente sociológico da ausência de mulheres musicistas na historiografia ainda carece de reflexão. Tentando reparar, mesmo que parcialmente, esse vazio, o texto enfatizará o trabalho musical feminino, algo que aponta para o surgimento de uma profissão possível para as mulheres no século XIX.

O convite feito pelo presente texto consiste em analisar a ação dessas musicistas na sociedade fluminense dos oitocentos como uma expressão do feminismo nascente nesse período'. Compreender a luta pela sobrevivência e sustento familiar por meio da música configura um modo não convencional de reação das mulheres e, portanto, uma nova abordagem sobre o feminismo no século XIX no Brasil; afinal, são modos de resistir e refazer a imagem sobre o ser feminino no país.

Para tornar conhecido esse contingente feminino, faremos uso de um método de investigação envolvendo a pesquisa de palavras-chave na Hemeroteca da Fundação Biblioteca Nacional no interior de algumas páginas da imprensa oitocentista. Tal método se inspira nas análises de Raymond Williams (2007) sobre o contexto inglês, que, guardadas as devidas proporções, foi reorientado para a compreensão do contexto brasileiro através da pesquisa em fontes primárias.

A partir das palavras-chave "compositora", "musicista", "pianista" e "professora de piano", partimos para uma pesquisa documental no acervo do Jornal do Commercio, no qual encontramos 84 nomes de mulheres que se ocupavam da atividade de ensino de piano e de canto e 101 nomes de compositoras no mesmo período. Cabe lembrar que havia mais mulheres para além das 84 referidas, contudo, elas não se apresentavam com seus nomes de batismo ou artísticos, por isso não pudemos contabilizá-las. Todavia, ao registrar o trabalho e as obras daquelas que se apresentavam com nome, estaremos de alguma maneira nos remetendo ao modo de vida de um grupo de artistas mulheres como um todo.

A pesquisa sobre o tema demonstra a relevância do ensino de música no plano de estudos de uma educação feminina. Tendo em vista que a forma socialmente aceita para uma mulher sobreviver naquele momento - e garantir a subsistência familiar, em muitos casos - foi por meio

\footnotetext{
${ }^{1}$ A título de exemplo seguem os nomes de alguns periódicos que debatiam temas ligados ao feminismo: Jornal das Senhoras (1852-1855); O Sexo Feminino(1875-1877 e retomado de 1877-1889); A Família (1889-1897); Jornal das Damas (1890); A Mensageira (1897-1900); e O Quinze de Novembro do Sexo Feminino (1890-1896) (BUITONI, 1980, p. 21-29).
} 


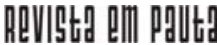

\} OS MODOS DE VIDA DAS MUSICISTAS - PAIXÃO, A. H.; PAULA, P. A. \}

DOI: $10.12957 /$ rep.2021.56081

do ensino de piano e de canto, o objetivo deste texto é justamente esboçar quem eram essas artistas, o que faziam e como faziam, de modo geral, mas também exemplificando com algumas trajetórias. O intuito, portanto, é o de reconstituir as experiências femininas que a história oficial insiste em não contar.

A imprensa carioca, mais especificamente a seção de anúncios, é o principal locus de pesquisa para uso desse método das palavras-chave. É neste espaço que se prova a existência de muitas professoras de piano, intérpretes e compositoras, sujeitos dessa pesquisa. Privilegiamos os jornais como fonte de pesquisa por serem compreendidos como meio de comunicação mais popular, voltados a assuntos ordinários de interesse comum e transmitidos no vernáculo. Nesse sentido, a linguagem escrita é pensada aqui como prática social e a ela está atrelado o desenvolvimento dos sentimentos populares de um tempo passado.

A intensa atividade de educação musical, as programações de concertos e os serviços editoriais de música que demonstram os anúncios do Jornal do Commercio, bem como outros periódicos analisados entre os anos de 1808 a 1899, são indicativos de uma ambiência favorável à circulação dessas mulheres musicistas, profissionais e amadoras, em espaços diversos da sociedade brasileira oitocentista, sobretudo na capital do Império. Sua atuação profissional se dava do ambiente doméstico das casas grandes (com as aulas particulares) aos salões aristocráticos (nos saraus e nos bailes), nos concertos em teatros e clubes e em espaços sociais mais restritos, como os colégios. Esse tipo de atividade feminina indica ainda um expediente comum entre as mulheres que de alguma maneira precisavam garantir seu sustento, seja por uma necessidade imposta por sua origem social, seja pela condição de imigração ou por uma fatalidade qualquer que as fez perder seus bens originais (endividamento familiar, falência ou perda de um parente).

É preciso dizer que numa sociedade de caráter patriarcal e de estrutura estamental-escravista, como a fluminense dos oitocentos ${ }^{2}$, que negava, sobretudo, o direito ao trabalho às mulheres das camadas sociais média e alta, a possibilidade de inscrição profissional feminina por meio do magistério e da música constituiu um avanço em seus modos de vida, um assunto que queremos introduzir e discutir. Sempre que utilizamos o termo modos de vida, estamos nos referindo à cultura de uma época como um processo social geral de "preenchimento completo da vida social", o qual se constrói com base na experiência cotidiana. Trata-se de uma escolha teórica apoiada no debate que vê "a cultura como algo comum", como pensado por Raymond Williams (2015), do qual nos apropriamos para refletir sobre o contexto da cultura brasileira oitocentista.

${ }^{2}$ Sobre a situação estamental-escravista do Brasil Império, ver as sínteses de Paixão (2017, p. 23). 


\section{Os modos de vida das musicistas na sociedade fluminense}

As mulheres que encontramos nesta pesquisa de doutorado em andamento eram contratadas não somente como professoras de piano e de canto (modo como se apresentavam nos anúncios), mas como professoras de línguas estrangeiras (francês, português, alemão e italiano), de humanidades (história, geografia, primeiras letras e desenho), de trabalhos de agulha (bordados) e também como governantas nas casas de boa reputação. Eram, em sua maioria, estrangeiras, mulheres idosas, de meia idade, viúvas ou jovens solteiras, recém-chegadas ao Brasil. Mas a partir da segunda metade do século XIX, começaram a aparecer mulheres brasileiras desempenhando essa atividade de ensino. Geralmente, ofereciam seus préstimos ou eram procuradas para atuar em colégios internos, em casas particulares ou em sua própria residência, e tinham como público-alvo meninas das chamadas boas famílias. Essas artistas se comprometiam a oferecer todas as matérias necessárias para a educação de uma senhora da alta sociedade, sob uma referência de padrões europeus da época ${ }^{3}$.

Elas apresentavam seus anúncios de trabalho ou eram procuradas geralmente entre as páginas destinadas aos anúncios diversos, tais como: venda, aluguel e recompensa pela captura de escravos fugidos, divulgação de serviços e produtos relacionados à saúde e à higiene, leilões diversos, serviços relacionados ao comércio de alimentos, serviços e produtos relacionados ao vestuário, aluguel de imóveis e de pessoas para trabalhos eventuais em residência e no comércio. A esse respeito, a professora de piano alemã, de línguas estrangeiras (alemão, inglês e francês) e de canto Ina von Binzer (1994, p. 67) fez um importante comentário: "[...] ando procurando no Jornal do Comércio o que me possa servir, entre os anúncios de pretos fugidos e vendas de escravos, que é onde também se pedem as professoras com imensa capacidade e inúmeras perfeições".

Ao oferecerem seus serviços nos anúncios dos jornais, as professoras de piano e de canto propunham o pagamento mensal ou por lição (os valores variavam entre $1 \$ 500$ e $2 \$$ por lição, ou de $10 \$$ a $20 \$$ por mês em residência própria ou particular). Também se dispunham a morar nos colégios internos (recebendo em torno de $5 \$$ por mês) ou em casas particulares, recebendo alimentação, roupa lavada, serviço médico e botica em troca de seu trabalho de ensino - é importante destacar que esses valores recebidos representavam muito pouco, conforme veremos a seguir (Figuras $1,2$ e 3$)$.

O conjunto de dados apresentados anteriormente permite-nos acessar muitos detalhes sobre a remuneração e as condições de trabalho nos colégios da época. Eles confirmam o suposto de que os valores recebidos pelas professoras representavam muito pouco, bem como o fato

${ }^{3}$ Jornal do Commercio (RJ) (1838, edição 00224; 1852, edição 00296; 8 mai. 1860, edição 00128; 1861, edição 00301; e 2 jul. 1864, edição 00183). 


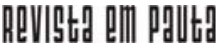

\} OS MODOS DE VIDA DAS MUSICISTAS - PAIXÃO, A. H.; PAULA, P. A. \}

DOI: $10.12957 /$ rep.2021.56081

de que o preço estipulado por lição nas aulas particulares era muito baixo. Quanto ao pagamento mensal de 10 a 20 mil réis, pela lógica, parece que era uma maneira de garantir um preço fixo mensal por aluna, o que na prática não se diferenciava muito do valor por aula (de 1 a 2 mil réis), visto que uma aluna fazia em média duas aulas por semana, conforme os anúncios analisados. O valor mensal assegurava ainda que as ausências da cliente não prejudicassem as finanças da professora. Além disso, pelos anúncios, notamos que as professoras buscavam preencher todos os horários vagos que tinham, o que aponta a necessidade de terem muitas alunas para suprir suas demandas financeiras.

Figura 1 - Jornal do Commercio (RJ), 1860, edição 00223

\section{Professora de piano.}

Ima sgnhora propóe-se a aceitar algunas meninas para aprender yiano, pelo diminuto preço de 18500 por lipuio, e bem assim a dar liçües por casas particulares ; poilem dirigir-se à rua dos Invalidos n. $62 \mathrm{~A}$.

Figura 2 - Jornal do Commercio (RJ), 1869, edição 00161

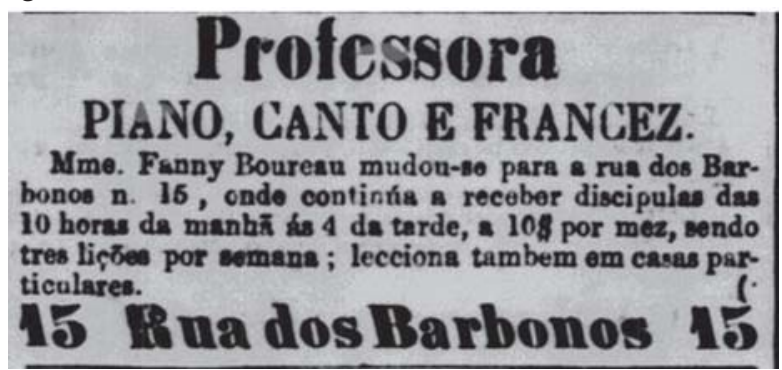

Figura 3 - Jornal do Commercio (RJ), 6 jan. 1872, edição 00006

\section{VASSOURAS.}

O 1lim. Sr. fazenciciro que mandou propór o ordenado de ?.600) á profcsara idosa de piano e canto, etc., para ir educar suas dignes, filbss, queira mandar ¿ rua de S. Jozé n. 5.

Mas, pela natureza do vínculo informal de trabalho por meio das aulas particulares por elas ministradas, é possível antever algumas dificuldades no que diz respeito ao seu efetivo pagamento. Sobre isso, tivemos acesso ao depoimento de Adèle Toussaint-Samson (de 1851) acerca da experiência vivida por uma amiga sua, que se viu nesta situação completamente desamparada: 
Uma das minhas amigas enviuvara, e ficando sem recursos pôs-se a dar lições de Francês e Desenho, para sustentar dois filhos, que o marido lhe deixara. A pobre senhora, de pé desde a madrugada, tendo apenas cinco horas de repouso, mal ou bem ia assim vivendo. Um dia foi procurar M. T..., pedindo-lhe que ajudasse a obter o pagamento de duzentos francos, que uma das suas discípulas Ihe devia desde muito tempo, e não queria pagar. Referia ela o fato, quando o nosso cônsul, interrompendo-a repentinamente:

- A senhora tem dívidas?

- Não, senhor; graças a um contínuo labor e à minha extrema economia, não as tenho, respondeu ela.

- É, portanto, muito mais feliz do que a pessoa de quem fala, replicou o santo homem, com voz mansinha. [...]

- Ela tem dívidas, a senhora não as tem; é portanto mais feliz do que ela. (LEITE, 1984, p. 128).

Quanto às condições de trabalho nos colégios, apresentamos um trecho da carta de Ina von Binzer à sua amiga Grete. Nele, ela relata sua rotina de trabalho num colégio para moças em 1882.

[...] desde anteontem estou contratada para um colégio daqui. Um colégio é um liceu de moças, com pensionato; tenho que lecionar quatro classes, iniciando as filhas deste país nos segredos das línguas alemã e inglesa; além disso darei inúmeras aulas de piano [...] Com a melhor boa vontade não cheguei ainda a calcular o número das minhas alunas de música. Quando me sento ao piano pela manhã, às seis e meia, elas começam a aparecer de meia em meia hora, até as dez horas, como se fossem expelidas por um relógio automático. Agora, tenho tomado nota de uma a uma, e à força de muito trabalho e astúcia espero estabelecer um cálculo exato. (BINZER, 1994, p. 81-82).

Além disso, ela descreve como as professoras estrangeiras viviam nos aposentos fornecidos por um colégio interno carioca:

Meu quarto é uma alcova sem janelas, dependente de uma sala de aulas e recebendo luz apenas através da porta. Sua mobília consiste somente numa cama (edição barata da de São Francisco), um lavatório, uma cadeira. Não tenho armário, nem cômoda. Minha mala serve de rouparia e para meus vestidos melhores espero poder conquistar as boas graças de Mlle. Serôt [diretora do colégio] para obter dela o armário dos castigos tornando-se credora da gratidão das crianças. Escrevo justamente do quarto da francesa que, apesar da tradicional inimizade, é com quem mais simpatizo nesta casa. Seu quarto é muito melhor que o meu, mas possui uma mesa e uma janelinha alta, perto do teto; ao passo que no meu buraco escuro, que existe em todas as casas brasileiras, sinto-me quase asfixiada. Devo acrescentar que neste prédio sofremos horrivelmente por causa das baratas, inseto escuro e repugnante, de cheiro pestilento, parecido com o nosso besouro de maio. (BINZER, 1994, p. 63-66). 


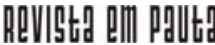

\} OS MODOS DE VIDA DAS MUSICISTAS - PAIXÃO, A. H.; PAULA, P. A. \}

DOI: $10.12957 /$ rep.2021.56081

Notamos pela leitura das cartas de Ina para a sua amiga que, na sua avaliação, era mais vantajoso o trabalho em residência particular, do ponto de vista da remuneração e da instalação oferecida, do que o trabalho no colégio.

No caso da oferta de trabalho em Vassouras, zona rural da província, conforme a Figura 3, cujo ordenado era de 2 contos, como aparenta pela escrita, é possível dizer que se tratava de uma oferta vantajosa diante do contexto. Porém, tal oferta implicava indiretamente que a professora tivesse disponibilidade para residir com a família na casa grande, pois o trânsito diário seria inviável. O próprio anúncio oferece um detalhe importante: procurava-se uma professora idosa, sendo viúva ou solteira, perfil no qual ela se encaixaria muito bem. Sobre este ponto, cabe precisar as condições de trabalho de uma professora de piano e de canto na fazenda para julgar por aí se o ordenado era justo ou não.

Aqui, as aulas são das sete às dez, depois vem o almoço quente, pelo qual Madame Rameiro nos faz esperar inutilmente até às dez e meia, de maneira que não posso mais sair, porque, logo após o último bocado, tenho de voltar às aulas. Prosseguimos até uma hora, quando temos então trinta minutos para o lanche; à uma e meia começam as aulas de piano que vão até às cinco, quando servem o jantar. Pergunto-lhe eu: quando poderei passear antes das seis? Veja se consegue descobrir outra hora melhor. Eles querem engolir cultura às colheradas e nunca têm uma tarde livre, um dia desocupado, nem muito menos uma semana de férias durante todo o ano. (BINZER, 1994, p. 31).

Por fim, analisamos a seguir o anúncio apresentado na Figura 4. Nele aparece outra modalidade de trabalho, o trabalho da professora de piano, canto e outras matérias não remunerado. Tratava-se de uma prática comum, conforme pudemos notar por meio de outros anúncios ${ }^{4}$.

Figura 4 - Jornal do Commercio (RJ), 1870, edição 00019

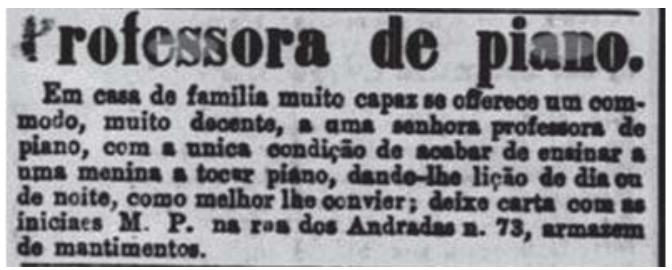

A princípio, encontramos duas formas de trabalho: remunerado e não remunerado, além de compreensões distintas sobre o trabalho de uma professora de piano e de canto. A presença do dinheiro ou relação

\footnotetext{
${ }^{4}$ A título de exemplo, indicamos os seguintes, ambos no Jornal do Commercio(RJ), de 1865, na edição 00198, e de 14 out. 1871, na edição 00284 .
} 


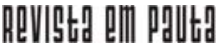

\} OS MODOS DE VIDA DAS MUSICISTAS - PAIXÃO, A. H.; PAULA, P. A.

DOI: $10.12957 /$ rep.2021.56081

salarial é incipiente e prematura no Brasil do século XIX, por isso trabalhamos também com o conceito de "vocação" ao pensar o trabalho artístico.

Nesse contexto, a compreensão que mais se aproxima desse ideal de vocação foi a desenvolvida por Guacira Louro (2008) acerca da vocação clérigo-leiga feminina no exercício do magistério. Suas bases admitem como princípio a forte influência religiosa católica, que esteve presente em boa parte das instituições educativas voltadas ao público feminino. É, portanto, uma espécie de estímulo ao desapego material na profissão, em que assuntos ligados ao salário, à carreira e às condições de trabalho podiam ficar em segundo plano. Por último, há a questão dos "atributos ditos femininos", como paciência, minuciosidade, afetividade, doação, cuidado, sensibilidade e amor (LOURO, 2008, p. 450-454).

Também não se pode desconsiderar que a compreensão por parte dessa sociedade patriarcal e escravocrata de que havia necessidade de se remunerar o trabalho feminino era muito recente. Todavia, as condições de vida das mulheres que se sujeitavam a essa experiência servil eram bastante hostis, e o fato de serem bem educadas não lhes proporcionava uma condição econômica estável, pois permaneciam desprovidas de posse e de renda.

Pela forma de apresentação dos anúncios, digamos, pelos seus enunciados, identificamos ainda a presença de distinções entre essas muIheres. Algumas delas estavam associadas à figura de grandes mestres e músicos de alto prestígio de seu tempo (Achille Arnaud, Sigismond Thalberg, Gennaro Arnaud, Henrique Herz, Louis Moreau Gottschalk, Arthur Napoleão, Archangelo Fiorito e Isidoro Bevilacqua, por exemplo). Além disso, possuíam um currículo que expressava uma formação canônica ${ }^{5}$, apresentando-se na cena pública em concertos nos teatros e nos salões. Enquanto isso, as outras eram tão somente professoras de piano anônimas que se apresentavam sob a escrita: "senhora", "viúva", "professora de piano" ou "mestra idosa", cujos termos revelam muito pouco sobre sua identidade. Assim, as hierarquias se apresentavam entre as musicistas de maior prestígio e as musicistas corriqueiras. Nesses termos, e repassando uma das assertivas de Williams $(1962,2015)$, devemos enfatizar não a escada, mas os processos comuns de interação mútua, aqueles que se dão nos espaços mais ordinários, sendo a seção dos anúncios da imprensa um espaço por excelência.

Embora fosse do interesse da maioria das professoras que encontramos se filiar aos colégios para ministrar o ensino de piano e de canto, identificamos somente alguns nomes associados a instituições educacionais, cujo público-alvo era, em sua maioria, feminino. São eles: Candida Francisca de Andrade (professora no Collegio Braga e no Collegio Costa Pereira), Clara Freese Tiberghien (diretora e professora do Collegio das Laranjeiras

${ }^{5} \mathrm{~A}$ ideia de cânone musical é ocidental e eurocêntrica. Ela revela os preceitos mais básicos de como a música funciona como disciplina, ditando como o indivíduo aprende dentro deste campo, como ele internaliza certos padrões e como não pode transgredi-los (WEBER, 1999). 
\} OS MODOS DE VIDA DAS MUSICISTAS - PAIXÃO, A. H.; PAULA, P. A. \}

DOI: $10.12957 /$ rep.2021.56081

para meninas), Claudina de Paula Menezes (professora da $2^{\underline{a}}$ cadeira no Magisterio Publico Primario da Freguezia de S. José para o sexo feminino), Condessa de Rozwadowska (professora no Collegio de Santa Cecilia para meninas), Francisca Pinheiro de Aguiar Barros (diretora do Collegio de Santa Cecilia para meninas), Rita Maria da Silveira (diretora e professora do Collegio União Infantil) e Sophia Emery (professora no Collegio da baroneza de Geslin).

Theodolinda Gerly não esteve associada a uma iniciativa institucionalizada de ensino, porém, após ter concluído seu contrato com a companhia de Ópera Lírica instalada no Theatro Lyrico, organizou em sua residência um curso de música com método próprio aprendido com o professor Pasquale Bona (1808-1878), do Conservatório de Milão. Ela se dedicou ao ensino de discípulas particulares e também de meninas pobres que desejassem aprender a tocar piano e cantar gratuitamente. Encontramos vários anúncios fazendo menção a esse fato, inclusive informando que as aulas se davam simultaneamente para pagantes e não pagantes, o que já nos assinala a não ocorrência de distinção no tratamento dado às suas alunas. Além disso, promovia anualmente concertos com suas discípulas e artistas convidados. Tal iniciativa demonstra certamente um impacto público do seu trabalho, independentemente de ele estar vinculado a uma instituição. Temos duas matérias que fazem menção ao fato; a última fala sobre um concerto dado com suas discípulas e artistas convidados como uma forte evidência da eficácia de seu método perante o público ouvinte. ${ }^{6}$

Partindo dessas ponderações, para matizarmos o ponto, vejamos alguns exemplos de trajetórias de musicistas, como a da Condessa Rafaela de Roswadowska (c. 1816-1906):

Compôs a primeira ópera escrita por uma compositora no Brasil (Dous Amores, drama lyrico em três atos, de 1861). De origem polonesa, era esposa do Conde de Roswadowsky, cidadão brasileiro, ex-major do Estado Maior do nosso exército, residente no Rio de Janeiro (AZEVEDO, 1938). Além da ópera, localizamos cinco composições para piano e um hino de sua autoria. Entre os anúncios, havia também uma recorrente oferta de suas aulas de piano, de canto, de composição e de italiano, bem como encontramos sua presença como concertista em importantes teatros cariocas de seu tempo, o que aponta uma necessidade por parte dela de ter uma boa remuneração atuando em vários serviços. Os anúncios a seguir (Figuras 5 e 6) demonstram a necessidade dessa artista de se destacar em relação às demais, ressaltando suas qualidades e seu nome.

Outro nome que merece destaque é o de Amélia de Mesquita (1866-1954). Natural da cidade do Rio de Janeiro, ela consolidou toda a sua carreira nesta cidade. Aos nove anos de idade já se destacava no colégio

${ }^{6}$ Correio Mercantil e Instructivo, Politico, Universal (RJ), 1858, edição 00122; Diario do Rio de Janeiro(RJ), 9 nov. 1861 , edição 00306. 


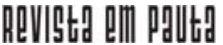

\} OS MODOS DE VIDA DAS MUSICISTAS - PAIXÃO, A. H.; PAULA, P. A. \}

DOI: $10.12957 /$ rep.2021.56081

religioso de S. Vicente de Paula pela execução ao piano com energia, habilidade e maestria. Em 1877 foi a Paris com a família, com o objetivo de que ela e o irmão, Carlos de Mesquita (1864-1953), pudessem ingressar no Conservatório de Música de Paris. Carlos ingressou primeiro (de 1877 a 1882) e Amélia teve o irmão como seu primeiro professor; depois ela mesma deu início aos seus estudos no Conservatório, tendo os mesmos professores que ele: ambos estudaram composição com Jules Massenet, piano com Antoine-François Marmontel, órgão com César Franck e harmonia com Émile Durand.

Figura 5 - Jornal do Commercio, 1857, edição 00172

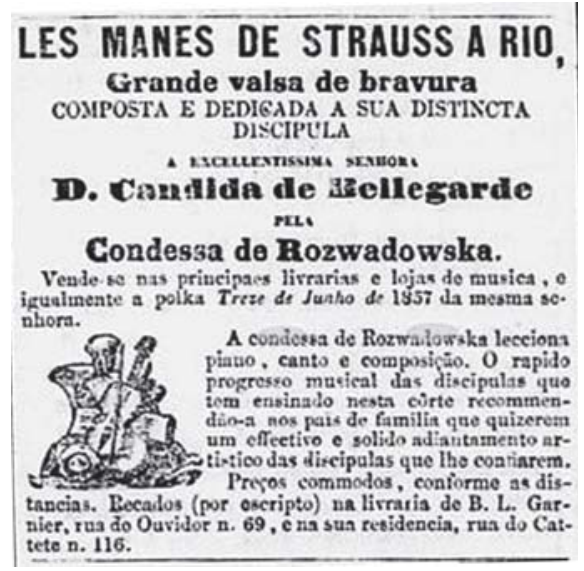

Após completar sua formação no Conservatório, ela retornou ao Brasil em 1885 e manteve até 1936 suas atividades como professora de piano, realizando regularmente audições de piano com suas alunas no salão nobre do Jornal do Commercio. Atuou como solista das principais orquestras da época, apresentando-se em diversas salas de concerto no Rio de Janeiro, sob a regência de maestros como Alberto Nepomuceno (18641920) e Vincenzo Cernicchiaro (1858-1928).

Em 1886 casou-se com Arthur da Fonseca Braga, um negociante. O casal teve dois filhos: Fernando de Mesquita Braga (diplomata) e Oswald Mesquita Braga (almirante e também pianista). Em 1890, localizamos uma ação de divórcio a pedido de Arthur da Fonseca Braga contra sua esposa, Amélia Mesquita da Fonseca Braga, da qual foi juiz Luiz Raymundo da Silva Brito, e advogado do autor o Dr. Galdino de Freitas Travassos. Acerca do desfecho desse divórcio não temos mais detalhes, mas um ano após esse pedido seu esposo veio a falecer. De qualquer forma, ela não deixou de ser apresentada com nome de casada nos jornais. Em 1912, foi nomeada professora de órgão e harmônio do Instituto Benjamin Constant ${ }^{7}$, onde

${ }^{7}$ A Imprensa (RJ), 1912, edição 01818. 
\} OS MODOS DE VIDA DAS MUSICISTAS - PAIXÃO, A. H.; PAULA, P. A. \}

DOI: $10.12957 /$ rep.2021.56081

Figura 6 - Correio Mercantil, e Instructivo, Político, Universal (RJ), 1862, edição 00014

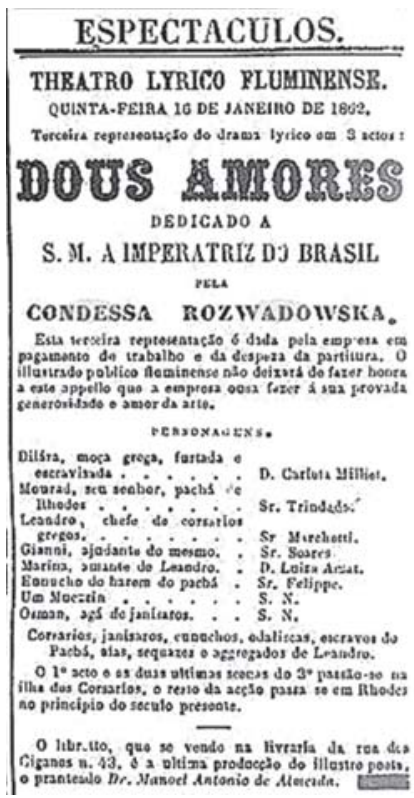

permaneceu trabalhando até os 70 anos de idade, aposentando-se com esta idade devido a um estado de saúde bastante debilitado.

Embora tenha gozado de uma carreira bem sucedida na sociedade fluminense, com constante presença na cena pública como concertista e boa recepção de suas composições, sobretudo nos gêneros música sacra e canção - das quais foram localizadas 16 peças, sendo uma delas a missa a duas vozes votiva a S. Christovão (1910), além de 34 peças cujas letras em sua maioria eram em vernáculo e algumas em francês. O primeiro e único vínculo institucional conquistado por Amélia ocorreu 27 anos após ter concluído sua formação. Já o seu irmão, depois de formado, não constituiu residência fixa no Brasil e passou boa parte da vida em Paris. Porém, sempre teve oportunidades de inserção institucional no país de origem - ele foi professor no Imperial Conservatório de Música e no Instituto Nacional de Música (de 1890 a 1893).

Vale mencionar também, ainda que em passos rápidos, que as produções às quais tivemos acesso até o momento apontam que Amélia de Mesquita fez significativas contribuições para a "canção de arte", merecendo destaque os seguintes títulos: A casa do coração (letra de Antero de Quental); Olhos negros (letra de Almeida Garrett); Restituição (letra de Francisco Octaviano); Sempre (letra de Maria Eugênia Celso); e O vira da passagem do ano (letra de Branca de Gonta Colaço). 


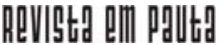

\} OS MODOS DE VIDA DAS MUSICISTAS - PAIXÃO, A. H.; PAULA, P. A.

DOI: $10.12957 /$ rep.2021.56081

Sobre a "canção de arte" no vernáculo, o nome que se consagrou neste gênero foi Alberto Nepomuceno (1864-1920), que era um compositor contemporâneo de Amélia, segundo Vasco Mariz (2002). O detalhe que não pode passar despercebido é que a visibilidade dada a Nepomuceno naquele momento estava associada ao projeto ideológico do regime republicano, que fazia dele músico oficial do regime (CARVALHO, 2012).

Múltiplos aspectos podem ter corroborado para as poucas referências ao legado de Amélia na historiografia musical: a ampla concorrência feminina é um deles, e sobretudo o sucesso de Chiquinha Gonzaga (18471935) pode ter tornado invisível o seu trabalho, bem como o de outras mulheres no mesmo período. Além disso, as condições materiais de existência dessa artista, o provável divórcio e a situação de viúva aos 25 anos de idade e com dois filhos pequenos para sustentar sozinha certamente tiveram impacto sobre suas escolhas como artista.

Outra trajetória que convém citar é a da professora de piano e normalista Claudina de Paula Menezes. Ela enviuvara do Dr. Francisco de Paula Menezes em $1857^{8}$, membro do Instituto Historico e Geographico Brasileiro, titular da cadeira de rethorica na Corte e no Collegio D. Pedro II. Embora seu marido tenha sido uma figura eminente, isto não a livrou, bem como a seus cinco filhos, de "uma honrosa mas triste pobreza, minorada felizmente pela munificencia imperial" ${ }^{\prime \prime}$, com a pensão anual de $600 \$ 000^{10}$, concedida por decreto de 26 de setembro de 1857, mas votada pela assembleia geral somente em 12 de junho de 1858. Contudo, a situação se agravaria a partir de 1860 por conta de um processo judicial da recorrente D. Thereza de Jesus Menezes sobre a recorrida D. Claudina de Paula Menezes. Esse processo se estendeu até 1866, segundo as fontes do periódico Correio Mercantil, e Instructivo, Politico, Universal (RJ). Não foi possível acessar o seu conteúdo na íntegra, somente algumas decisões que permitem inferir o seguinte: a recorrente, ao que parece, pretendia ser tutora dos filhos menores de Claudina, cujo objetivo aparenta ter sido conquistado. Claudina recorreu; passou a embargante e recorrente contra Thereza de 1861 a $1862^{11}$, e em $1865^{12}$, como inventariante do Dr. Francisco de Paula Menezes, Ihe foi demandado que indicasse pessoa idônea para tutoria dos menores, fazendo com que a suplicante Claudina assinasse o termo de renúncia e prestasse fiança em $1866^{13}$.

Essa longa explanação serve para expor o drama vivido por Claudina de Paula Menezes e também a sua capacidade de reação. Em 1861, movida provavelmente pela necessidade de garantir sustento, ela passou a

\footnotetext{
${ }^{8}$ Jornal do Commercio (RJ), 11 set. 1857, edição 00250.

${ }^{9}$ Correio Mercantil, e Instructivo, Politico, Universal(RJ), 18 dez. 1857, edição 00345.

${ }^{10}$ Jornal do Commercio (RJ), 11 jun. 1858, edição 00158, e Diario do Rio de Janeiro (RJ), 17 jun. 1858, edição 00162.

${ }^{11}$ Correio Mercantil, e Instructivo, Politico, Universal (RJ), 4 ago. 1861, edição A00212; 10 abr. 1862, edição 00099 ; e jun. 1862, edição 00189.

${ }^{12}$ Correio Mercantil, e Instructivo, Politico, Universal (RJ), 1 dez. 1865, edição 00327.

${ }^{13}$ Correio Mercantil, e Instructivo, Politico, Universal (RJ), 5 nov. 1866, edição 00306.
} 
\} OS MODOS DE VIDA DAS MUSICISTAS - PAIXÃO, A. H.; PAULA, P. A. \}

DOI: $10.12957 /$ rep.2021.56081

oferecer seus préstimos como professora de piano em casas particulares, conforme anúncio a seguir (Figura 7).

Figura 7 - Correio Mercantil, e Instructivo, Politico, Universal (RJ), 26 jan. 1861

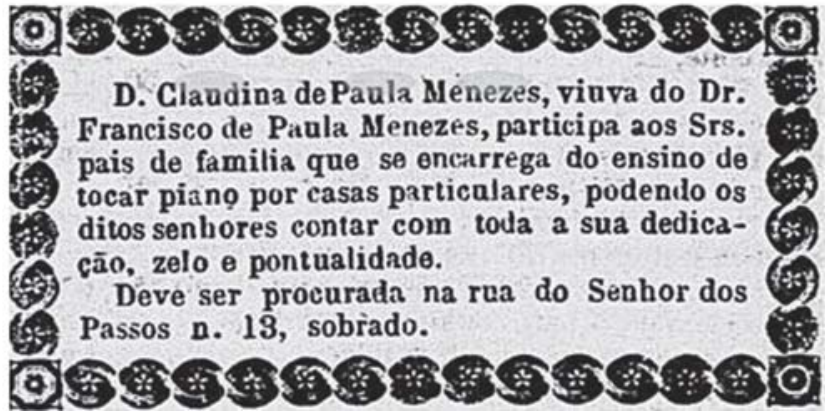

A partir de 1867 seus anúncios deixam de estar associados à figura do falecido marido ${ }^{14}$. Em 1869 ela concluiu o Curso Normal pela Escola da Província do Rio de Janeiro ${ }^{15}$. Em 1871 foi aprovada em concurso para provimento de cadeira na instrução pública ${ }^{16}$, e no ano seguinte foi nomeada para segunda cadeira da escola pública de instrução primária feminina de S. José $\mathrm{e}^{17}$.

O itinerário de Claudina de Paula Menezes demonstra o sofrimento comum de uma mulher viúva, com filhos e desprovida de posses e renda nessa sociedade, ao passo que também aponta que a única saída para essa mulher em situação de desamparo financeiro e emocional consistia na educação que ela teve. $\mathrm{O}$ fato de ter sido professora de piano e canto foi a sua salvação, foi o que lhe permitiu o acesso a uma profissão formal.

\section{Considerações finais}

A construção analítica proposta neste artigo, de certo modo, permite atribuir à experiência de Claudina de Paula Menezes e à de Ina von Binzer uma relação de semelhança ao modo de vida de outras professoras de piano e de canto, no qual o ofício de musicista desponta como uma reação e abre espaço para um legado vocacional que funde arte musical e trabalho remunerado.

As condições de vida dessas mulheres muitas vezes obrigavamnas a se sujeitarem a experiências servis e bastante hostis, como nos casos

\footnotetext{
${ }^{14}$ Jornal do Commercio (RJ), 1867, edição 00355.

${ }^{15}$ Diario do Rio de Janeiro (RJ), 12 dez. 1869, edição 00342.

${ }^{16}$ Brasil. Ministério do Império: Relatorio da Repartição dos Negocios do Imperio (RJ), 1871, edição 00001.

${ }^{17}$ Almanak Administrativo, Mercantil e Industrial do Rio de Janeiro (RJ), 1872, edição 00029.
} 
referidos das professoras de piano e de canto em casas particulares e em colégios internos, bem como daquelas que trabalhavam em troca de moradia, alimentação e botica. Conforme vimos, a vocação clérigo-leiga feminina no exercício do magistério estava associada ao cuidado, logo, uma atividade que no interior de uma sociedade escravocrata e patriarcal não prescindia de remuneração.

Em todo extenso levantamento feito, não localizamos um anúncio sequer de oferta ou de procura de ofício voltado aos músicos homens, condicionando e sujeitando somente as mulheres a este tipo de trabalho não remunerado e sem prestígio. $O$ fato de esse contingente feminino encontrar-se desprovido de posse e de renda reforçava sua vulnerabilidade, fazendo com que estivesse sempre dependente de seu próprio trabalho ou dos "favores" de outrem.

Assim, esculpimos o esboço de um perfil feminino das musicistas descobertas entre os anúncios do Jornal do Commercio e também de outros periódicos. A análise neles desenvolvida pretendeu interpretar alguns sinais de vida dessas mulheres, obscurecidos por um universo musical predominantemente masculino. Note-se que a prerrogativa da formação canônica que muitas delas compartilhavam estava centrada no legado masculino. Entretanto, nessa perspectiva, Marcia Citron (1993) discute como o conjunto de expectativas autoimpostas se diferenciam para homens e mulheres profissionais da música. Geralmente, as mulheres estão menos presas aos padrões canônicos, mais liberadas para a escrita e execução de gêneros intelectualmente menos ambiciosos e mais populares, o que se justifica nesse caso porque elas buscavam incessantemente sobreviver por meio da música e encontravam-se em relação desigual perante os homens.

Outro aspecto significativo debatido é que a inscrição profissional dessas mulheres e o ensino de música por elas desempenhado promoveu algo para além da imagem dominante que se tinha da mulher carioca oitocentista. Pelo caminho analítico percorrido, viu-se que: a promoção da escolarização, o contato com o mundo letrado, a presença do piano nas casas, bem como a frequência nos teatros, nos bailes e nas lojas de música promoveram uma reconfiguração da sociedade no sentido de conservar a base do patriarcado, mas também de expor as ambiguidades, as transgressões vividas pelas mulheres. Segundo Saffioti e Almeida (1995, p. 178), a transgressão pode referir-se "à construção de contrapoderes e de ressignificação de valores e vivências". Os exemplos reais apresentados ao longo do texto somente reforçam essa assertiva. 


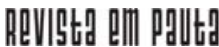

\} OS MODOS DE VIDA DAS MUSICISTAS - PAIXÃO, A. H.; PAULA, P. A. \}

DOI: $10.12957 /$ rep.2021.56081

\section{Referências}

AZEVEDO, L. H. C. Escala, ritmo e melodia na música dos índios brasileiros. Rio de Janeiro: Rodrigues \& Cia, 1938.

BINZER, I. Os meus romanos: alegrias e tristezas de uma educadora alemã no Brasil. Rio de Janeiro: Paz e Terra, 1994.

BUITONI, D. H. S. Mulher de papel: a representação da mulher na imprensa feminina brasileira. Tese (Doutorado em Linguística) - Departamento de Linguística e Línguas Orientais, USP, São Paulo, 1980.

CARVALHO, D. V. O gênero da música: a construção social da vocação. São Paulo: Alameda, 2012.

CITRON, M. J. Gender and the musical canon. Cambridge: Cambridge University Press, 1993.

LEITE, M. M. (Org.). A condição feminina no Rio de Janeiro, século XIX: antologia de textos de viajantes estrangeiros. São Paulo: HUCITEC/Pró-Memória, 1984.

LOURO, G. L. Mulheres na sala de aula. In: PRIORE, M. D. (Org.). História das mulheres no Brasil. São Paulo: Contexto, 2008.

MARIZ, V. A canção popular brasileira. Rio de Janeiro: Editora Francisco Alves, 2002.

PAIXÃO, A. H. Leitores de tinta e papel: elementos constitutivos para o estudo do público literário no século XIX. Campinas: Mercado de Letras, 2017.

SAFFIOTI, H. I. B.; ALMEIDA, S. S. Violência de gênero: poder e impotência. Rio de Janeiro: Revinter, 1995.

WEBER, W. The history of musical canon. In: COOK, N.; EVERIST, M. Rethinking music. New York: Oxford University Press, 1999.

WILLIAMS, R. Communications. London: Penguin, 1962.

WILLIAMS, R. Palavras-Chave: um vocabulário de cultura e sociedade. São Paulo: Boitempo, 2007.

WILLIAMS, R. Recursos da esperança. São Paulo: Editora Unesp, 2015.

DOI: $10.12957 /$ rep.2021.56081

Recebido em 09 de março de 2020.

Aprovado para publicação em 25 de agosto de 2020.

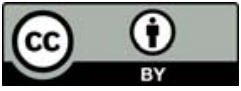

A Revista Em Pauta: Teoria Social e Realidade Contemporânea está licenciada com uma Licença Creative Commons Atribuição 4.0 Internacional. 